\title{
Plume-lithosphere interaction, and the formation of fibrous diamonds
}

\author{
M.W. Broadley ${ }^{1,2 *}$, H. Kagi ${ }^{1}$, R. Burgess ${ }^{3}$, D. Zedgenizov ${ }^{4,5}$, S. Mikhail ${ }^{6}$, \\ M. Almayrac ${ }^{2}$, A. Ragozin ${ }^{4,5}$, B. Pomazansky7 ${ }^{7}$ H. Sumino ${ }^{8}$
}

Abstract

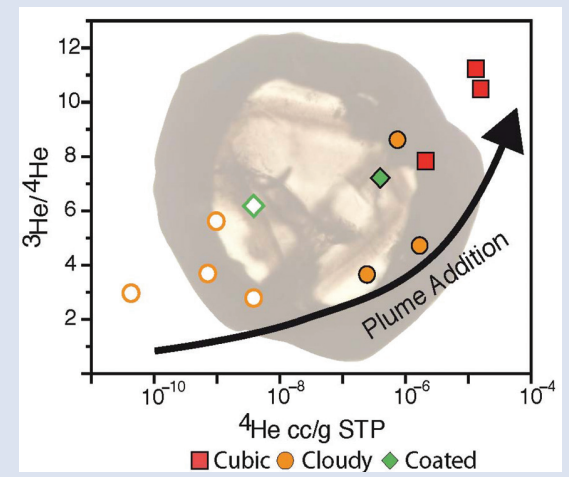

Fluid inclusions in diamond provide otherwise inaccessible information on the origin and nature of carbonaceous fluid(s) in the mantle. Here we evaluate the role of subducted volatiles in diamond formation within the Siberian cratonic lithosphere. Specifically, we focus on the halogen $(\mathrm{Cl}, \mathrm{Br}$ and I) and noble gas (He, Ne and Ar) geochemistry of fluids trapped within cubic, coated and cloudy fibrous diamonds from the Nyurbinskaya kimberlite, Siberia. Our data show Br/ $\mathrm{Cl}$ and $\mathrm{I} / \mathrm{Cl}$ ratios consistent with involvement of altered oceanic crust, suggesting subduction-derived fluids have infiltrated the Siberian lithosphere. ${ }^{3} \mathrm{He} /{ }^{4} \mathrm{He}$ ranging from 2 to $11 \mathrm{R}_{\mathrm{A}}$, indicates the addition of a primordial mantle component to the SCLM. Mantle plumes may therefore act as a trigger to re-mobilise subducted carbon-rich fluids from the sub-continental lithospheric mantle, and we argue this may be an essential process in the formation of fluid-rich diamonds, and kimberlitic magmatism.

Received 5 May 2018 | Accepted 14 September 2018 | Published 1 October 2018

\section{Introduction}

Diamond formation events within the sub-cratonic lithospheric mantle (SCLM) are related to metasomatism, often coeval with tectonothermal events, such as subduction and plume emplacement (Haggerty, 1999; Gurney et al., 2010). These fluids can be trapped as microinclusions along the surfaces of diamond fibres and surrounding diamond-hosted mineral inclusions (Navon et al., 1988; Nimis et al., 2016; Skuzovatov et al., 2016). Diamond-hosted fluids therefore represent the only direct samples of mantle fluids, and provide a unique insight into the composition of carbonaceous fluids from the mantle.

Fluids trapped in diamonds are categorised into four major compositional groups, distinguishable on a ternary plot for $\mathrm{K}+\mathrm{Na}$ (saline), $\mathrm{Al}+\mathrm{Si}$ (silicic), and $\mathrm{Ca}+\mathrm{Mg}+\mathrm{Fe}$ (highand low-Mg carbonatitic) (Klein-BenDavid et al., 2009). The four compositional end members are considered to form either via immiscible separation of hydrous and carbonatitic fluids within the SCLM (Schrauder and Navon, 1994), or via the interaction of a parental saline fluid with the lithosphere, producing silicic and carbonatitic fluids (Weiss et al., 2015). Saline fluids in diamonds have been shown to have high concentrations of $\mathrm{Cl}$ of up to 40 wt. \% (Izraeli et al., 2001; Klein-BenDavid et al., 2007). Diamonds from Canadian kimberlites, previously shown to contain saline inclusions (Tomlinson et al., 2009) have highly elevated $\mathrm{Br} / \mathrm{Cl}$ and $\mathrm{I} / \mathrm{Cl}$ values, suggesting parental fluids may have been introduced to the SCLM during ancient subduction-related processes (Johnson et al., 2000).

Halogens and noble gases are concentrated in surface reservoirs, and have distinguishable elemental/isotopic ratios within different reservoirs, making them sensitive tracers of subduction-related metasomatism (Broadley et al., 2016). Here we report halogen abundance $(\mathrm{Cl}, \mathrm{Br}$ and $\mathrm{I})$ and noble gas isotopic (He, $\mathrm{Ne}$ and $\mathrm{Ar}$ ) data from a suite of cubic, cloudy and coated diamonds from the Nyurbinskaya kimberlite, Nakynsky field, Siberia (Fig. S-1). The Nyurbinskaya kimberlite contains a higher proportion of eclogitic diamonds, relative to other Siberian kimberlites - potentially indicating the diamonds have a subduction-related origin (Spetsius et al., 2008). We combine halogen and noble gases to explore the origin(s) of diamond-hosted fluids within the Siberian SCLM.

\footnotetext{
Geochemical Research Center, Graduate School of Science, The University of Tokyo, Hongo, Bunkyo-ku, Tokyo 113-0033, Japan

. Centre de Recherches Pétrographiques et Géochimiques, 54501 Vandoeuvre-Lès-Nancy Cedex, France

School of Earth and Environmental Science, University of Manchester, Oxford Road, Manchester M13 9PL, UK

Sobolev Institute of Geology and Mineralogy, SB RAS, Koptyuga ave. 3, Novosibirsk 630090, Russia

Novosibirsk State University, Pirogova st. 1, Novosibirsk 630090, Russia

The School of Earth and Environmental Sciences, The University of St. Andrews, St. Andrews, UK

NIGP (Geo-Scientific research Enterprise) ALROSA Co., Chernyshevskoe rd. 7, 678170, Mirny, Sakha Republic, Russia

Department of Basic Science, Graduate School of Arts and Sciences, The University of Tokyo, Tokyo 153-8902, Japan

Corresponding author (email: broadley@crpg.cnrs-nancy.fr)
} 


\section{Halogen Geochemistry}

The range of $\mathrm{Cl}(0.5-20.3 \mathrm{ppm}), \mathrm{Br}(2.7-168.6 \mathrm{ppb})$ and $\mathrm{I}$ (0.1-2.1 ppb) concentrations within the diamonds ( $\mathrm{n}=7$; Table S-1) are higher than previously reported measurements of Siberian fibrous diamonds (Burgess et al., 2002). Halogen concentrations are higher in cubic diamonds indicating that halogens are predominantly sited within microinclusions, given the greater proportion of inclusions in the cubic diamonds compared to the coated or cloudy samples.

The $\mathrm{Br} / \mathrm{Cl}$ and $\mathrm{I} / \mathrm{Cl}$ ratios for the fluids progress from mantle-like signatures towards elevated $\mathrm{Br} / \mathrm{Cl}$ values (Fig. 1) Similar $\mathrm{Br} / \mathrm{Cl}$ signatures have been previously measured in fibrous diamonds from Canada (Johnson et al., 2000; Burgess et al., 2009). The above mantle $\mathrm{Br} / \mathrm{Cl}$ and $\mathrm{I} / \mathrm{Cl}$ values in Canadian diamond-fluids were attributed to either the subduction of volatiles into the SCLM or fractionation of halogens during the separation of immiscible fluids (Burgess et al., 2009). The latter process was considered most feasible given the lack of a known subduction component with similar $\mathrm{Br} / \mathrm{Cl}$ and $\mathrm{I} / \mathrm{Cl}$ values (Burgess et al., 2009).

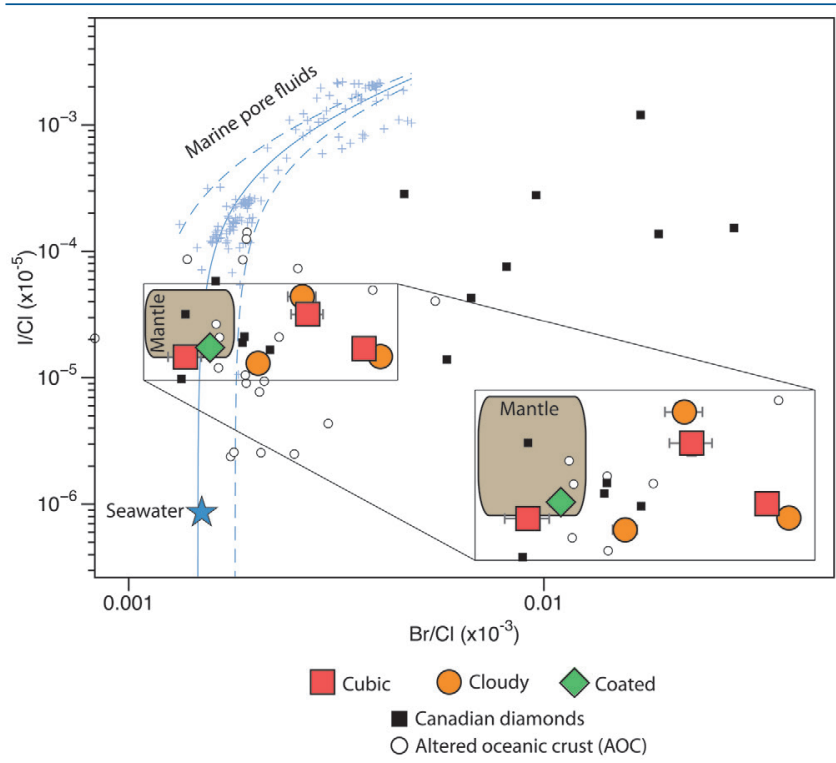

Figure 1 Log-log plot of $\mathrm{I} / \mathrm{Cl}$ vs. $\mathrm{Br} / \mathrm{Cl}$ (mol/mol) for the Nyurbinskaya diamonds. Seawater, average mantle, marine pore fluids, altered oceanic crust fluids (AOC) and Canadian diamonds are shown for reference (Johnson et al., 2000; Muramatsu et al., 2007 and references therein; Kendrick et al., 2012; Chavrit et al., 2016). Nyurbinskaya diamonds range from mantle values towards enriched $\mathrm{Br} / \mathrm{Cl}$, similar to $\mathrm{AOC}$ and Canadian diamonds suggesting there has been an input of Br-rich fluids to the Siberian lithosphere. Uncertainties are $1 \sigma$ when shown and are often smaller than symbol size.

However, the separation of immiscible fluids during diamond formation would likely lead to combined fractionation of both $\mathrm{Br} / \mathrm{Cl}$ and $\mathrm{I} / \mathrm{Cl}$ ratios. The $\mathrm{I} / \mathrm{Cl}$ ratio is expected to be fractionated to a greater degree given that halogen fractionation is most likely controlled by differences in solubility in the aqueous fluid, which increases from $\mathrm{NaCl}<\mathrm{NaBr}<$ $\mathrm{NaI}$, leading to the heavier halogens being concentrated in the brine fraction, relative to the lighter halogens (Bureau et al., 2000). Fractionation should therefore result in a steeper profile of $\mathrm{Br} / \mathrm{Cl}$ and $\mathrm{I} / \mathrm{Cl}$ than that measured in the Nyurbinskaya and Canadian diamonds (Johnson et al., 2000). The $\mathrm{I} / \mathrm{Cl}$ of Nyurbinskaya diamonds are also consistently mantle-like, suggesting fractionation during diamond formation is not the main mechanism controlling the increase in $\mathrm{Br} / \mathrm{Cl}$. To explain the relative enrichment in Br without an associated enrichment of I, is therefore more consistent with mixing between two distinct components (mantle-like + high $\mathrm{Br} / \mathrm{Cl}$ component; Fig. 1).

A potential high $\mathrm{Br} / \mathrm{Cl}$ source is the fluid fraction trapped within altered oceanic crust (AOC) (Chavrit et al., 2016). High $\mathrm{Br} / \mathrm{Cl}$ in $\mathrm{AOC}$ fluids is attributed to phase separation of saline fluids during seawater-basalt interaction, and/or the sequestering of $\mathrm{Cl}$ into alteration minerals (Chavrit et al., 2016). This process fractionates $\mathrm{Br} / \mathrm{Cl}$, whereas $\mathrm{I} / \mathrm{Cl}$ ratios remain mostly intermediate between mantle and seawater values. This suggests that interaction between seawater and the oceanic crust with a mantle composition predominantly controls I/ $\mathrm{Cl}$, without affecting $\mathrm{Br} / \mathrm{Cl}$, given that seawater and mantle have indistinguishable $\mathrm{Br} / \mathrm{Cl}$ values. Higher than mantle $\mathrm{I} / \mathrm{Cl}$ in $\mathrm{AOC}$ may indicate a limited degree of fractionation or the presence of an I-rich sedimentary component (Fig. 1; Chavrit et al., 2016). Whilst Nyurbinskaya and Canadian diamonds generally range from mantle values towards higher $\mathrm{Br} / \mathrm{Cl}$ and $\mathrm{I} / \mathrm{Cl}$, some diamonds have $\mathrm{I} / \mathrm{Cl}$ lower than the mantle, which could not be formed from the same fractionation process responsible for the elevated $\mathrm{Br} / \mathrm{Cl}$ and $\mathrm{I} / \mathrm{Cl}$ and may therefore signify a subducted AOC component in the parental fluids (Fig. 1).

Mantle xenoliths from Nyurbinskaya show $\delta^{18} \mathrm{O}$ values up to $+9.65 \%$ o, higher than typical mantle samples $(+5.5 \%$ o; Mattey et al., 1994). Elevated $\delta^{18} \mathrm{O}$ is interpreted as evidence for subduction of oceanic crust, which has undergone low temperature alteration (Gregory and Taylor, 1981). Notably, $\mathrm{Br} / \mathrm{Cl}$ of $\mathrm{AOC}$ fluids decreases with depth in the oceanic crust (Chavrit et al., 2016), suggesting the release of fluids from the upper oceanic crust, where low temperature alteration occurs, may be the potential source of the halogen-rich fluids within the Siberian SCLM. The subduction of AOC fluids can therefore provide a $\mathrm{Br} / \mathrm{Cl}$ enriched source necessary to explain the signature of the Nyurbinskaya diamonds.

An $\mathrm{AOC} \mathrm{Br} / \mathrm{Cl}$ and $\mathrm{I} / \mathrm{Cl}$ origin could also account for some of the values measured within other fibrous diamonds (Fig. 1). The extreme $\mathrm{Br} / \mathrm{Cl}$ and $\mathrm{I} / \mathrm{Cl}$ measured in some Canadian diamonds cannot be accounted for by the simple addition of AOC-like fluids to the SCLM, suggesting that another process may be responsible for enriching diamond-forming fluids in $\mathrm{Br}$ and I relative to $\mathrm{Cl}$. This process may be related to an unknown fractionation process during subduction or within the SCLM, however the processes driving further enrichment of $\mathrm{Br}$ and I remain unknown.

\section{Noble Gas Geochemistry}

The ${ }^{3} \mathrm{He} /{ }^{4} \mathrm{He}$ of the diamonds released during crushing and laser heating are similar and range from 2.8-11.2 $\mathrm{R}_{\mathrm{A}}$. However, the concentrations of He released during laser heating are 2-4 orders of magnitude lower than that released during crushing (Fig. 2), suggesting the noble gases are primarily hosted within microinclusions and are efficiently released by crushing. The upper range of ${ }^{3} \mathrm{He} /{ }^{4} \mathrm{He}$ in the diamonds is similar to values obtained from Siberian Flood Basalts (<12.7; Basu et al., 1995) indicating that the diamonds contain at least two noble gas components; a low ${ }^{3} \mathrm{He} /{ }^{4} \mathrm{He}$ SCLM component and a high ${ }^{3} \mathrm{He} /{ }^{4} \mathrm{He}$ primitive mantle component, potentially related to the Siberian plume. The ${ }^{3} \mathrm{He} /{ }^{4} \mathrm{He}$ signatures of the diamonds differ according to type, with the cubic diamonds having ${ }^{3} \mathrm{He} /{ }^{4} \mathrm{He}$ extending above the MORB range ( $8 \pm 1 R_{A} ;$ Graham, 2002), whilst the coated and cloudy diamonds range from MORBlike to lower values. The cubic diamonds therefore appear to be dominated by volatiles associated with the plume-like signature, whilst coated and cloudy diamonds retain more of the original lithospheric signature $\left(4-6 R_{A}\right.$; Gautheron 


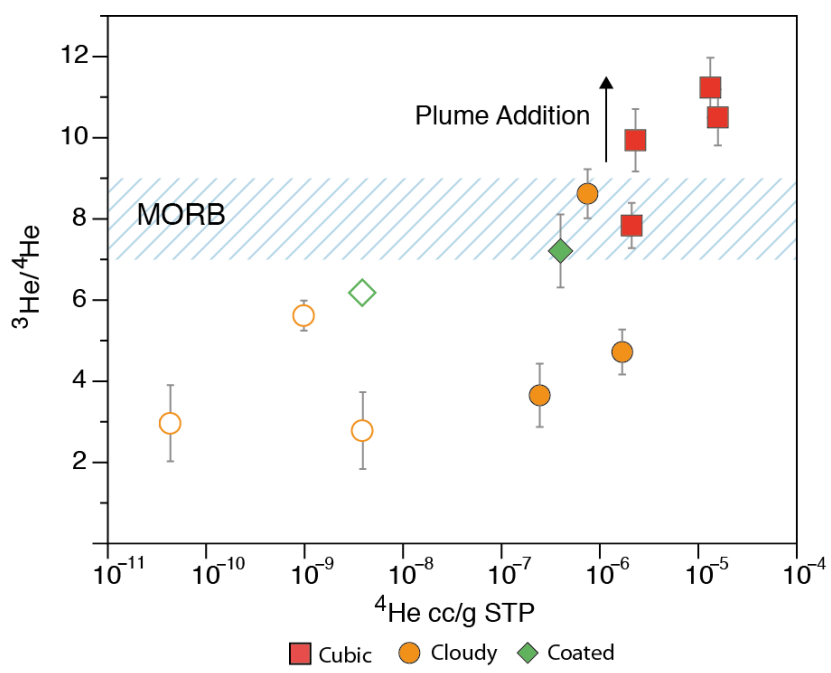

Figure $2{ }^{3} \mathrm{He} /{ }^{4} \mathrm{He}$ vs. ${ }^{4} \mathrm{He}$ concentrations from crushing and laser heating (open symbols) of Nyurbinskaya diamonds. ${ }^{3} \mathrm{He} /{ }^{4} \mathrm{He}$ from the cubic diamonds are higher than the cloudy and coated diamonds and plot above MORB values suggesting the diamond-hosted inclusions contain a mixture of lithospheric and deep mantle volatiles. Uncertainties shown are $1 \sigma$ and for ${ }^{4} \mathrm{He}$ concentrations are smaller than symbol size.

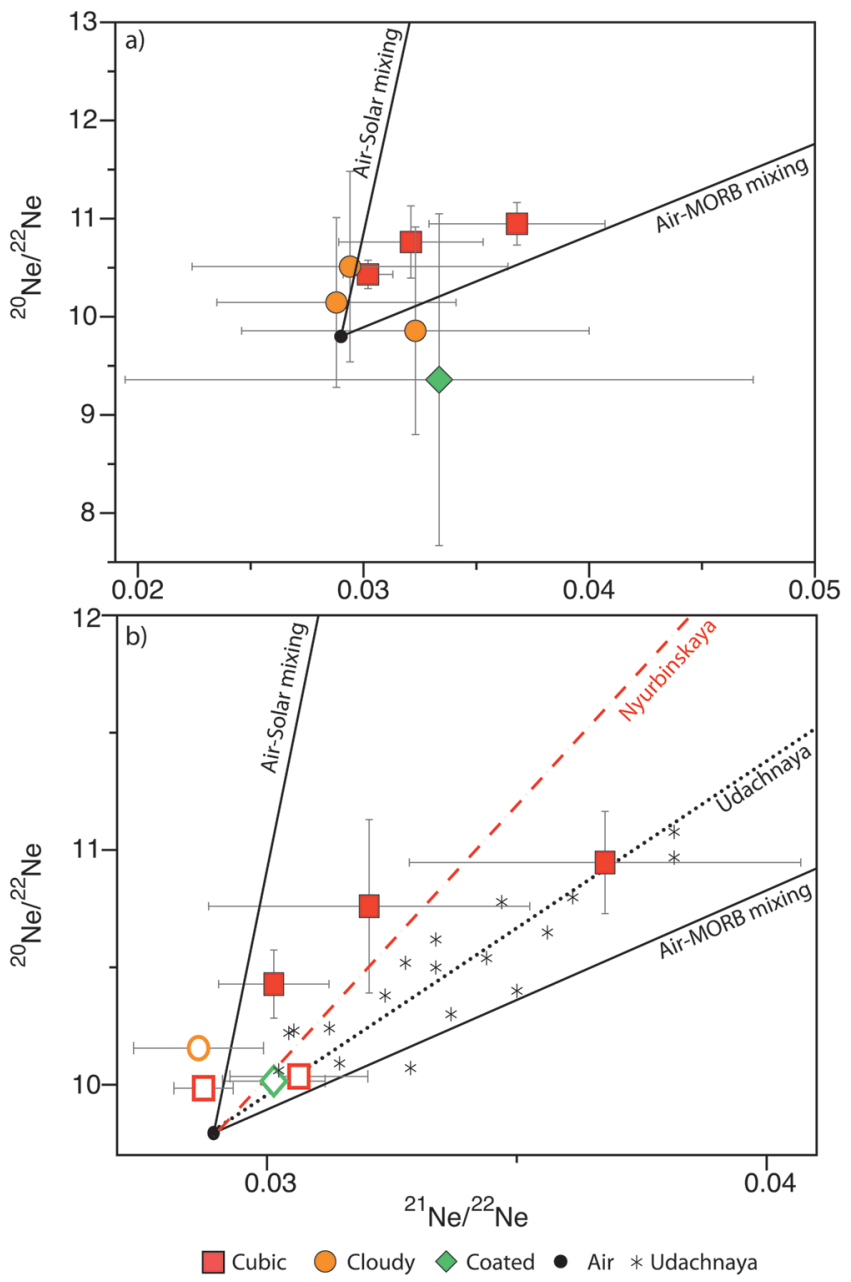

Figure 3 (a) Neon three-isotope plot for crushing of Nyurbinskaya diamonds. (b) Zoomed in section showing data from laser extraction (open symbols) plus the crushing data from the cubic diamonds. Diamonds show excess in ${ }^{20} \mathrm{Ne} /{ }^{22} \mathrm{Ne}$ and ${ }^{21} \mathrm{Ne} / 22 \mathrm{Ne}$ relative to air and plot intermediate between the MORB-Air mixing line and the Solar-Air mixing line. Dashed red line is a regression line fitted through all the Nyurbinskaya diamond data and forced through the atmospheric values. Dashed black line is the trend for Udachnaya olivine xenocrysts (Sumino et al., 2006). Uncertainties are $1 \sigma$.

et al., 2005). Some of the coated and cloudy diamonds have lower than SCLM ${ }^{3} \mathrm{He} /{ }^{4} \mathrm{He}$ suggesting the additional input of radiogenic ${ }^{4} \mathrm{He}$ to the SCLM from a subducted component (Barry et al., 2015).

Neon isotopic ratios from the Nyurbinskaya diamonds further indicate the involvement of a mantle plume in the Siberian SCLM. Diamonds with $\mathrm{Ne}$ isotopic ratios distinct from atmosphere (Fig. 3) are intermediate between the Air-MORB mixing line and the Air-Solar mixing line on the ${ }^{20} \mathrm{Ne} /{ }^{22} \mathrm{Ne}-$ ${ }^{21} \mathrm{Ne} /{ }^{22} \mathrm{Ne}$ isotope diagram. The neon isotope composition of Nyurbinskaya diamonds is similar to those from Udachanaya (Sumino et al., 2006), suggesting that the formation of kimberlites and fibrous diamonds in the Siberian Craton around 360 Ma may be linked to the injection of plume material. The $\mathrm{He}$ and $\mathrm{Ne}$ isotopic composition of Nyurbinskaya diamonds indicates that they contain a mixture of air and a mantle end member, the latter having high ${ }^{3} \mathrm{He} /{ }^{4} \mathrm{He}$ and mantle-like ${ }^{20} \mathrm{Ne} /{ }^{22} \mathrm{Ne}$ compositions similar to the Siberian Flood Basalts, with an additional contribution from the low ${ }^{3} \mathrm{He} /{ }^{4} \mathrm{He}$ SCLM (Fig. S-5).

\section{Diamond Formation during Plume- Lithosphere Interaction}

The nitrogen aggregation state in diamonds provides a qualitative method to investigate the mantle residence time and temperature of diamonds (Supplementary Information). Nitrogen aggregation states of fibrous diamonds indicate they have short mantle residence times, and ${ }^{40} \mathrm{Ar}-{ }^{39} \mathrm{Ar}$ ages of fibrous coats suggests their growth is related to kimberlite magmatism (Taylor et al., 1996; Burgess et al., 2002). Low nitrogen aggregation states determined for Nyurbinskaya cubic and cloudy diamonds (Fig. 4) confirm that they formed not long before emplacement. The core of the coated diamonds however, show nitrogen aggregation states more consistent with a mantle residence age of between $1 \mathrm{Ma}$ and $200 \mathrm{Ma}$ based on a residence temperature of $1200-1300{ }^{\circ} \mathrm{C}$, as estimated from mantle xenoliths in the nearby Udachnaya kimberlite (Boyd et al., 1997). Individual FTIR measurements on the coats of the fibrous samples show low degrees of $\mathrm{N}$ aggregation, indicating fibrous coats formed around the same time and resided at similar mantle temperatures, as the cubic diamonds.

Cubic diamonds, which are most abundant in microinclusions and have very short mantle residence times, have the most plume-like noble gas signature suggesting that the fluids may be related to the influx of deep mantle volatiles triggering diamond growth. In contrast, the optically clearer diamond cores of the coated stones have a consistently larger percentage of nitrogen B centres suggesting a longer residence time as well as potentially acting as seeds for the growth of fibrous coats. It should be noted that given the temperature range estimated for the Siberian SCLM at the time of Nyurbinskaya kimberlite formation, all except some of the cloudy diamonds could have mantle residence as low as $5 \mathrm{Ma}$ and therefore may be related to the same metasomatic event(s). Three cubic diamonds that have similar nitrogen contents and aggregation states as the coated diamonds may indicate that even the cubic diamonds retain older diamond cores (i.e. seeds), or that the higher temperatures associated with plume accelerated the nitrogen aggregation state over short time scales (Fig. 4).

Therefore, the Siberian lithosphere experienced at least two episodes of diamond growth. The formation of fibrous diamonds in particular requires the precipitation of carbon 


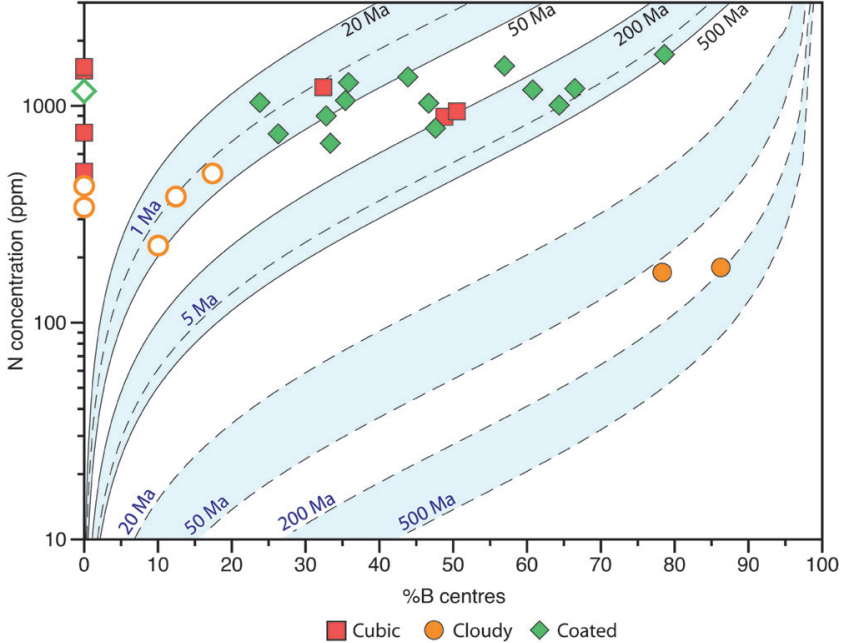

Figure 4 Total nitrogen concentrations vs. the percentage of nitrogen in the B aggregated state. Each point is from the analysis of a single diamond, full symbols are from the bulk measurement, whilst open symbols are from the fibrous coat or cloudy interior of the coated and cloudy diamonds respectively. Isotherms are calculated assuming a temperature range between $1200{ }^{\circ} \mathrm{C}$ (solid lines) and $1300{ }^{\circ} \mathrm{C}$ (dashed lines) as reported for Udachnaya xenolith (Boyd et al., 1997) and assumed residence times between $1 \mathrm{Ma}$ and $200 \mathrm{Ma}$. All diamonds indicate a residence time of less than $200 \mathrm{Ma}$ at the temperature estimated for the Siberian SCLM at 360Ma (eruption age of Nyurbinskaya and Udachnaya kimberlites).

from supersaturated fluids (Sunagawa, 1984), either during the progressive cooling of the $\mathrm{C}-\mathrm{O}-\mathrm{H}$ metasomatic fluids or from a change in the oxidation state where upon dissolved carbon can be precipitated as diamond (Klein-BenDavid et al., 2010). Cooling of C-O-H fluids as they interact with the surrounding lithosphere causes a decrease in the solubility of carbon leading to the supersaturation of the fluid and precipitation of diamond (Stachel and Luth, 2015).

Carbon isotopes in the cores of fibrous diamonds from the Sytykanskaya kimberlite in Yukutia extend from mantlelike to light $\delta^{13} \mathrm{C}$ values ( -3.8 to $-19.7 \%$ o) indicating that the Siberian craton contains a subducted carbon component (Skuzovatov et al., 2012). Fibrous diamonds often appear to be genetically linked to the last episode of metasomatism within the SCLM, possibly associated with kimberlite magmatism (Burgess et al., 2002), although there is evidence for the formation of fibrous diamond in older metasomatic events (Zedgenizov et al., 2006). The input of plume mantle material to the Siberian SCLM (Sumino et al., 2006) may therefore have re-mobilised subducted halogen (this study) and carbon-rich material (Jacob et al., 2000) already present within the lithosphere, leading to the precipitation of fibrous diamonds, and fibrous coats around a previous generation of diamonds within the Siberian SCLM.

\section{Acknowledgements}

This work was financially supported though a JSPS international research fellowship PE 14721 (to MWB) and JSPS KAKENHI grant numbers JP 26287139 and JP15KK0150 (to HS). The work of DAZ and ALR was supported by Russian science foundation (16-17-10067). RB acknowledges funding from the NERC (NE/M000427/1). SM acknowledges funding from the NERC (NE/PO12167/1). We also appreciate the constructive comments from Yaakov Weiss and an anonymous reviewer, which contributed greatly to our manuscript.

\section{Additional Information}

Supplementary Information accompanies this letter at http:// www.geochemicalperspectivesletters.org/article1825.

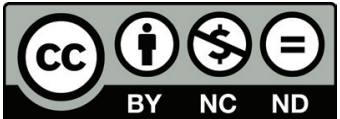

This work is distributed under the Creative Commons Attribution Non-Commercial No-Derivatives 4.0 License, which permits unrestricted distribution provided the original author and source are credited. The material may not be adapted (remixed, transformed or built upon) or used for commercial purposes without written permission from the author. Additional information is available at http://www.geochemicalperspectivesletters.org/ copyright-and-permissions.

Cite this letter as: Broadley, M.W., Kagi, H., Burgess, R., Zedgenizov, D., Mikhail, S., Almayrac, M., Ragozin, A., Pomazansky, B., Sumino, H. (2018) Plume-lithosphere interaction, and the formation of fibrous diamonds. Geochem. Persp. Let. $8,26-30$

\section{References}

Barry, P.H., Hilton, D.R., Day, J.M., Pernet-Fisher, J.F., Howarth, G.H., Magna, T., Agashev, A.M., PoKhilenko, N.P., PoKHILENKO, L.N., TAYLOR, L.A. (2015) Helium isotopic evidence for modification of the cratonic lithosphere during the Permo-Triassic Siberian flood basalt event. Lithos 216, 73-80.

Basu, A.R., Poreda, R.J., Renne, P.R., Teichmann, F., Vasiliev, Y.R., SoboleV, N.V., TurRin, B.D. (1995) High- ${ }^{3} \mathrm{He}$ plume origin and temporal-spatial evolution of the Siberian flood basalts. Science 269, 822-825.

Boyd, F.R., Pokhilenko, N.P., Pearson, D.G., Mertzman, S.A., Sobolev, N.V., Finger, L.W. (1997) Composition of the Siberian cratonic mantle: evidence from Udachnaya peridotite xenoliths. Contributions to Mineralogy and Petrology 128, 228-246.

Broadley, M.W., Ballentine, C.J., Chavrit, D., Dallai, L., Burgess, R. (2016) Sedimentary halogens and noble gases within Western Antarctic xenoliths: Implications of extensive volatile recycling to the sub continental lithospheric mantle. Geochimica et Cosmochimica Acta 176, 139-156.

Bureau, H., KeppleR, H., MÉTRich, N. (2000) Volcanic degassing of bromine and iodine: experimental fluid/melt partitioning data and applications to stratospheric chemistry. Earth and Planetary Science Letters 183, 51-60.

Burgess, R., Layzelle, E., Turner, G., Harris, J.W. (2002) Constraints on the age and halogen composition of mantle fluids in Siberian coated diamonds. Earth and Planetary Science Letters 197, 193-203.

Burgess, R., Cartigny, P., Harrison, D., Hobson, E., Harris, J. (2009) Volatile composition of microinclusions in diamonds from the Panda kimberlite, Canada: Implications for chemical and isotopic heterogeneity in the mantle. Geochimica et Cosmochimica Acta 73, 1779-1794.

Chavrit, D., Burgess, R., Sumino, H., Teagle, D.A., Droop, G., Shimizu, A., Ballentine, C.J. (2016) The contribution of hydrothermally altered ocean crust to the mantle halogen and noble gas cycles. Geochimica et Cosmochimica Acta 183, 106-124.

Gautheron, C., Moreira, M., Allègre, C. (2005) He, Ne and Ar composition of the European lithospheric mantle. Chemical Geology 217, 97-112.

GraHAM, D.W. (2002) Noble gas isotope geochemistry of mid-ocean ridge and ocean island basalts: Characterization of mantle source reservoirs. Reviews in mineralogy and geochemistry 47, 247-317.

GREGORY, R.T., TAYLOR, H.P. (1981) An oxygen isotope profile in a section of Cretaceous oceanic crust, Samail ophiolite, Oman: Evidence for $\delta^{18} \mathrm{O}$ buffering of the oceans by deep $(>5 \mathrm{~km})$ seawater-hydrothermal circulation at mid-ocean ridges. Journal of Geophysical Research 86, 2737-2755.

Gurney, J.J., Helmstaedt, H.H., Richardson, S.H., Shirey, S.B. (2010) Diamonds through time. Economic Geology 105, 689-712.

HAGGERTY, S.E. (1999) A diamond trilogy: superplumes, supercontinents, and supernovae. Science 285, 851-860.

IZRAELI, E.S., HARRIS, J.W., NAVON, O. (2001) Brine inclusions in diamonds: a new upper mantle fluid. Earth and Planetary Science Letters 187, 323-332. 
Jacob, D.E., Viljoen, K.S., Grassineau, N., JagoutZ, E. (2000) Remobilization in the cratonic lithosphere recorded in polycrystalline diamond Science 289, 1182-1185.

Johnson, L.H., Burgess, R., Turner, G., Milledge, H.J., Harris, J.W. (2000) Noble gas and halogen geochemistry of mantle fluids: comparison of African and Canadian diamonds. Geochimica et Cosmochimica Acta 64, 717-732.

Kendrick, M.A., Kamenetsky, V.S., Phillips, D., Honda, M. (2012) Halogen systematics (Cl, Br, I) in mid-ocean ridge basalts: a Macquarie Island case study. Geochimica et Cosmochimica Acta 81, 82-93.

Klein-Bendavid, O., Izraeli E.S., Hauri E., Navon, O. (2007) Fluid inclusions in diamonds from the Diavik mine, Canada and the evolution of diamond-forming fluids. Geochimica et Cosmochimica Acta 71, $723-744$.

Klein-Bendavid, O., Logvinova, A.M., Schrauder, M., Spetius, Z.V., Weiss, Y., Hauri, E.H., Kaminsky, F.V., Sobolev, V., Navon, O. (2009) High-Mg carbonatitic microinclusions in some Yakutian diamonds-a new type of diamond-forming fluid. Lithos 112, 648-659.

Klein-Bendavid, O., Pearson, D.G., Nowell, G.M., Ottley, C. McNeill, J.C., Cartigny, P. (2010) Mixed fluid sources involved in diamond growth constrained by $\mathrm{Sr}-\mathrm{Nd}-\mathrm{Pb}-\mathrm{C}-\mathrm{N}$ isotopes and trace elements. Earth and Planetary Science Letters 289, 123-133.

MatTey, D., LOWRY, D., MACPHERSON, C. (1994) Oxygen isotope composition of mantle peridotite. Earth and Planetary Science Letters 128, 231-241.

Muramatsu, Y., Doi, T., Tomaru, H., Fehn, U., Takeuchi, R., MatsuMOTO, R. (2007) Halogen concentrations in pore waters and sediments of the Nankai Trough, Japan: Implications for the origin of gas hydrates. Applied Geochemistry 22, 534-556.

Navon, O., Hutcheon, I.D., Rossman, G.R., WAsserburG, G.J. (1988) Mantle-derived fluids in diamond micro-inclusions. Nature 335, 784.

Nimis, P., Alvaro, M., Nestola, F., Angel, R.J., Marquardt, K., Rustioni, G., Harris., J.W., Marone, F. (2016) First evidence of hydrous silicic fluid films around solid inclusions in gem-quality diamonds. Lithos 260, 384-389.

SCHRAUdER, M., NAVON, O. (1994) Hydrous and carbonatitic mantle fluids in fibrous diamonds from Jwaneng, Botswana. Geochimica et Cosmochimica Acta 58, 761-771.

Skuzovatov, S., Zedgenizov, D., Howell, D., Griffin, W.L. (2016) Various growth environments of cloudy diamonds from Malobotuobia kimberlite field (Siberian craton). Lithos 265, 96-107.

Skuzovatov, S.Y., Zedgenizov, D.A., Ragozin, A.L., Shatsky, V.S (2012) Growth medium composition of coated diamonds from the Sytykanskaya kimberlite pipe (Yakutia). Russian Geology and Geophysics 53, 1197-1208

Spetsius, Z.V., TAYlor, L.A., VAlley, J.W., DeANGelis, M.T., SPICUZZA, M., IVANOV, A.S., BANZERUK, V.I. (2008) Diamondiferous xenoliths from crustal subduction: garnet oxygen isotopes from the Nyurbinskaya pipe, Yakutia. European Journal of Mineralogy 20, 375-385.

StACHEL, T., LUTH, R.W. (2015) Diamond formation-Where, when and how? Lithos 220, 200-220.

Sumino, H., KaneokA, I., Matsufui, K., Sobolev, A.V. (2006) Deep mantle origin of kimberlite magmas revealed by neon isotopes. Geophysical Research Letters 33, L16318, doi: 10.1029/2006GL027144.

SunAGAWA, I. (1984) Morphology of natural and synthetic diamond crystals. In: Sunagawa, I. (Ed.) Materials Science of the Earth's Interior. Terra Scientific Publishing Co., Tokyo, 303-330.

Taylor, W.R., Canil, D., Milledge, H.J. (1996) Kinetics of Ib to IaA nitrogen aggregation in diamond. Geochimica et Cosmochimica Acta 60, 4725-4733.

TOMLINSON, E.L., MÜlLER, W., EIMF (2009) A snapshot of mantle metasomatism: Trace element analysis of coexisting fluid (LA-ICP-MS) and silicate (SIMS) inclusions in fibrous diamonds. Earth and Planetary Science Letters 279, 362-372.

Weiss, Y., McNeill, J., Pearson, D.G., Nowell, G.M., Ottley, C.J. (2015) Highly saline fluids from a subducting slab as the source for fluid-rich diamonds. Nature 524, 339.

Zedgenizov, D.A., Harte, B., Shatsky, V.S., Politov, A.A., Rylov, G.M., SobolEV, N.V. (2006) Directional chemical variations in diamonds showing octahedral following cuboid growth. Contributions to Mineralogy and Petrology 151, 45-57. 